\title{
Psicología
}

Artículo de Reflexión

\section{El Interaccionismo Simbólico de Mead y el Argumento en favor del Indeterminismo de Popper}

\section{Mead's Symbolic Interactionism and Karl Popper's Argument for Indeterminism}

Isabel Cristina Posada Zapata ${ }^{1 凶} \underline{\mathrm{ORCID}}$; Jaime Alberto Carmona Parra ${ }^{2} \underline{\underline{\mathrm{ORCID}}}$

1 Doctora en Ciencias Sociales Niñez y Juventud CINDE/Universidad de Manizales. Profesora Universidad de Antioquia, Facultad Nacional de Salud Pública. Medellín, Colombia.

2 Doctor en Psicología Social, Posdoctorado en Ciencias Sociales, Niñez y Juventud. Coordinador de investigaciones y posgrados de la facultad de ciencias sociales y humanas de la Universidad de Manizales y profesor del Doctorado en Ciencias Sociales, Niñez y Juventud del CINDE/Universidad de Manizales, Colombia.

Fecha correspondencia:

Recibido: noviembre 1 de 2019.

Aceptado: junio 15 de 2021.

Forma de citar:

Posada Zapata, I., \& Carmona

Parra, J. (2021). EI

Interaccionismo Simbólico de Mead y el Argumento en favor del Indeterminismo de Popper. Rev. CES Psico, 14(3), 171-190. https://dx.doi.org/10.21615/ cesp.5599

\section{Open access}

(C) Derecho de autor

Licencia creative commons

Ética de publicaciones

Revisión por pares

Gestión por Open Journal System

DOI: 10.21615/cesp.5599

ISSNe: $2011-3080$

Publica con nosotros

\section{Resumen}

El artículo presenta un recorrido por algunas expresiones discursivas del Determinismo y el Indeterminismo, desde la Grecia Clásica hasta la Ciencia Moderna, como preámbulo para comprender el lugar del Interaccionismo Simbólico de George Mead en las Ciencias Sociales, para luego explorar la relación de ésta perspectiva teórica y metodológica con una propuesta de Karl Popper expuesta en su texto póstumo "El Universo Abierto, un argumento en favor del Indeterminismo " y mostrar las potentes y posibles articulaciones entre ambas perspectivas. De esta revisión puede concluirse que el Interaccionismo se sitúa como una solución dialéctica entre los postulados del Determinismo y del Indeterminismo, en la que se ofrece la perspectiva de un ser humano activo que, como agente, construye su vida en la interacción con otros referentes simbólicos. El agente como actor se sitúa en un plano donde deviene como producto y productor de su vida a partir del lenguaje.

Palabras clave: determinismo, indeterminismo, interaccionismo, interaccionismo simbólico, reflexividad, agenciamiento, George Mead, Karl Popper. 


\section{Abstract}

The article presents a journey through some discursive expressions of Determinism and Indeterminism, from Classical Greece to Modern Science, as a preamble to understand the place of George Mead's Symbolic Interactionism in Social Sciences, and then explore the relationship of this theoretical perspective and methodological with a proposal by Karl Pooper exposed in his posthumous text "An Argument for Indeterminism" and show the powerful possible articulations between both perspectives. From this review it can be concluded that Interactionism is situated as a dialectical solution between the postulates of Determinism and Indeterminism, where the perspective of an active human being is offered, who as an agent, builds his life in the interaction with other symbolic referents. The agent as an actor is situated on a plane where he becomes a product and producer of his life from language.

Keywords: determinism, indeterminism, interactionism, reflexivity, agency, symbolic interactionism, George Mead, Karl Popper.

\section{Introducción}

Dos doctrinas filosóficas que han acompañado el pensamiento occidental desde la Antigua Grecia hasta la actualidad y que han estado en la base de los debates de las Ciencias Sociales desde su nacimiento son el Determinismo y el Indeterminismo. En el primero se entiende que todos nuestros actos son fruto de leyes de la naturaleza o consecuencia de actos pasados, y el segundo se trata de la posibilidad que un sujeto pueda elegir por lo menos entre dos opciones, sin determinación por las leyes naturales o por eventos del pasado (Miranda, 2017). Las manifestaciones de ambas doctrinas filosóficas se pueden encontrar desde las tragedias griegas, pasando por la filosofía, la religión y la literatura, hasta la ciencia moderna.

En este artículo, en un primer momento se hará un recorrido por algunas expresiones discursivas representativas del Determinismo y el Indeterminismo en los ámbitos de la tragedia, la filosofía, la religión, la literatura y la ciencia, relacionadas con el devenir individual y colectivo de los seres humanos. En un segundo momento nos apoyaremos en este recorrido para mostrar posibles articulaciones del pensamiento interaccionista de George Herberth Mead con la propuesta que hace Karl Popper en su obra "El Universo Abierto, un argumento en favor del Indeterminismo", para mostrar que ambos autores coinciden en una visión del mundo y de las acciones humanas que afirma la existencia de un indeterminismo relativo: un universo natural y humano, en parte determinado, en parte probabilístico y en parte abierto. 
Esta visión se apoya en la perspectiva filosófica interaccionista que propone una resolución dialéctica de la antinomia entre determinismo e indeterminismo en sus versiones radicales. Bajo esta perspectiva interaccionista el ser humano es un emergente de la interacción dialéctica entre sus determinaciones naturales y sociales, de un lado, y del otro su agenciamiento, es decir, su condición de actor social activo que se construye y se transforma a sí mismo y a la sociedad que lo construye y lo transforma también. Cuando se piensa en la agencia, se plantea que la persona no se auto produce o se hace a sí misma, sino que el agenciamiento se produce como movimiento entre los actores y las entidades, se trata de un ensamblaje en lo colectivo (Raglianti, 2018). Es decir, que el interaccionismo concibe al ser humano como creador y creado, transformador y transformado, productor y producto del universo simbólico que habita, lo cual es congruente con el indeterminismo relativo propuesto por Karl Popper en el texto póstumo mencionado.

\section{El Determinismo}

El Determinismo afirma que el universo y el devenir humano están regidos por leyes que gobiernan de manera inexorable el acontecer natural y humano. Esta idea la podemos encontrar en expresiones que van desde las tragedias griegas hasta la ciencia moderna. Un ejemplo por excelencia en la Grecia Antigua es la historia del Rey Edipo, en ésta, los esfuerzos de Layo y Edipo por contrariar el destino que les había sido revelado por el oráculo, los empujan al cumplimiento de la profecía. Aunque Layo es alejado desde niño de su hogar para evitar la profecía, el destino lo lleva a encontrar a su padre en un camino y matarlo, asumiéndolo como un desconocido, para luego casarse con la esposa de él, su propia madre, dando así cumplimiento a todo lo que el oráculo había determinado que pasaría:

"No hubiera sido posible el matador de mi padre, no hubiera sido llamado por los hombres el esposo de la que he nacido. Pero hoy tengo a los dioses en contra mía; soy hijo de un tronco abominable, y miserable de mí, ihe fecundado el seno del cual nací! iSi hay alguna desgracia más grande que la desgracia misma, ésta ha sido la que ha tocado en suerte a Edipo!" (Sófocles, 2001, p. 37).

En el campo religioso también es posible encontrar expresiones del Determinismo. En el texto La Ética Protestante y el Espíritu del Capitalismo (2012), Max Weber aborda una versión religiosa del determinismo en el dogma de la "predestinación", como la creencia según la cual Dios ya ha decidido, antes del nacimiento de cualquier ser humano, si está predestinado a salvarse o a condenarse, de tal forma que todos los destinos de los seres humanos están escritos a la manera de guión inexorable. En palabras de Weber, esta predestinación deja de 
lado la posibilidad de una posición y comportamientos éticos en el individuo, pues habita un universo que está marcado por una designación divina, que está más allá de sus propias posibilidades, un destino determinado donde él no es agente:

"Así, pues, el tradicionalismo económico, que en los comienzos es producto de la indiferencia paulina, va derivando en fruto de la creencia, siempre más arraigada, de la predestinación, que identifica la obediencia incondicional a los preceptos divinos y la incondicional resignación con el lugar en que cada uno se encuentra colocado en el mundo. (...) La integridad de la doctrina, como único e infalible criterio de su Iglesia, sostenida por él (Lutero) con progresivo rigor después de veinte años de esforzada lucha, constituía en sí un impedimento para esclarecer consideraciones en el plano de la ética." (Weber 2012, p. 49).

En el campo literario, Jorge Luis Borges expresa frecuentemente la idea del Determinismo en sus escritos. Un cuento suyo titulado "Biografía de Tadeo Isidoro Cruz" inicia con el siguiente epígrafe: "I'm looking for the face I had before the world was made" (yo estoy buscando el rostro que tuve antes de que el mundo fuera hecho) (Borges, 2001). En otro de sus textos dirá: "lo que llamamos azar es nuestra ignorancia de la compleja maquinaria de la causalidad" (Borges, 1998, p.88). Lo que nos señala Borges en sus escritos literarios es que el destino es una marca inexorable, y que aunque no lo conozcamos, él está allí esperándonos sin remedio alguno.

No sólo en la tragedia griega, la religión y la literatura encontramos expresiones del Determinismo, éste también ha sido fundamento del desarrollo de teorías científicas. En el campo de las ciencias sociales, el Determinismo se expresa en el positivismo y su pretensión de la predictibilidad plena del comportamiento humano. En esta perspectiva, conocer la situación de los objetos y de las fuerzas que los determinan, harían posible predecir el futuro, de una forma más o menos precisa (Audi, 2004). Esta perspectiva parte de la premisa según la cual la mente humana puede conocer las leyes que gobiernan los fenómenos naturales y sociales, y como parte de ellos, las acciones humanas. Estas leyes expresan regularidades y nos permiten llegar tanto a las causas de los hechos como a la predicción del comportamiento que en el futuro tendrán éstos (Avila, 2008). Este pensamiento positivista, en intenso auge durante el siglo XIX, permitiría el florecimiento de la psicología y la sociología como disciplinas que se separaron de la filosofía para apoyarse en los métodos de las ciencias naturales, aceptando así la tesis positivista de la unidad de la ciencia (Garrido \& Alvaro, 2007). 
Uno de los más grandes expositores del Determinismo en el campo de la epistemología moderna fue el matemático francés Pierre Simon Laplace (1749-1827), quien postuló una visión determinista del mundo y el principio de la Razón Suficiente. De acuerdo con esta visión, hasta la más libre de las voluntades está plenamente determinada. Bajo la perspectiva laplaciana se trata de soluciones aplicables no sólo al ámbito de lo local, las leyes así descritas son soluciones para ecuaciones de orden global (González \& Alcodea, 2006). En palabras de Laplace:

Deberíamos entonces considerar el estado presente del universo como el efecto de su anterior estado y como la causa de la que está por seguir. Si por un instante una inteligencia pudiera comprender todas las fuerzas por las cuales la naturaleza está animada y la situación respectiva de los seres que lo componen, una inteligencia suficientemente amplia para analizar estos datos, abarcaría en la misma fórmula los movimientos de los cuerpos más grandes del universo y los del átomo más ligero; para esa inteligencia nada sería incierto y el futuro como el pasado, estaría presente ante sus ojos (Laplace, 1952, pp.3-4).

En esta vía de pensamiento se instaló el método científico del Determinismo Positivista en las ciencias sociales, buscando leyes universales que apuntalaran explicaciones generalizables de las acciones de los seres humanos y la predictibilidad de los hechos futuros. De ello dan cuenta ciertas aproximaciones estructuralistas de la sociología o biologicistas en psicología, o en el psicoanálisis que argumentaba que se trataba de una ciencia del determinismo de la vida psíquica de los seres humanos; lo que le valió a la postura freudiana más de una crítica dado que reclamaba el origen de toda conducta en la infancia de los sujetos, y con ello su desresponsabilización. En la actualidad la polémica no ha cesado, lo que sí puede afirmarse es que el determinismo hace una concatenación de hechos de manera que se niega la existencia de la libertad (Salcedo, 2010), pues es la estructura o los procesos neurobiológicos los que vienen a determinar los comportamientos de los grupos y los individuos.

Esta manera de explicar todo fenómeno de investigación desde el enfoque determinista se ha traducido en abordajes positivistas que tratan de abordar a través de modelos causales todo aquello que acontece con lo humano, incluyendo lo social. En este sentido, el positivismo se ocupa de las cosas, siendo la realidad aquello que existe y que pasa por los sentidos para ser objeto de conocimiento, y es sólo allí que se encuentra la verdad, asumiendo que lo social y lo humano son también cosas que pueden medirse y controlarse. Para aprehender tal realidad vienen en ayuda del positivismo las ciencias físicas y naturales que permiten conocer el fenómeno y sus causas, dejando de lado los enunciados valorativos pues ellos no hacen parte 
de esa realidad objetiva que quiere conocerse: la realidad es objetiva y empírica. Desde esta óptica, la ciencia para ser ciencia ha de desarrollarse desde un monismo metodológico experimental, métodos físicos y matemáticos y buscar la causalidad de las cosas para poder predecirlas en modelo, negando cualquier aproximación hermenéutica o interpretativa para el conocimiento de la realidad (Guamán, Hernández, \& Lloay, 2020).

\section{El Indeterminismo}

El Indeterminismo nace en el campo de la Filosofía, también en la Grecia Antigua. Podemos encontrar algunas expresiones suyas en el campo de la religión y la literatura y algunos desarrollos en el campo de las Ciencias Sociales. Lo que caracteriza los discursos indeterministas es que parten del principio de la plena autodeterminación para la comprensión del comportamiento y las vicisitudes de la vida de los seres humanos.

Una de sus expresiones históricas más reconocidas en el campo de la filosofía y la religión es, sin duda, la idea del "libre albedrío" en San Agustín. Según éste, Dios en su omnipotencia y omnisapiencia, si bien podría determinar de antemano la salvación o la condena de cada ser humano, decide darle la capacidad para distinguir el bien y el mal, y la libertad para elegir el camino de la salvación (San Agustín, 2017). Como se puede observar, se trata de una perspectiva claramente opuesta al dogma protestante de la predestinación.

Una metáfora literaria que puede ilustrar el Indeterminismo, del hombre que libremente se hace a sí mismo, la podemos encontrar en la novela inglesa Robinson Crusoe. El héroe de Daniel Defoe (2017) es un paradigma del hombre que construye solo su propio mundo después del naufragio. Este rasgo quedó objetivado en el lenguaje bajo la forma de un neologismo: el "robinsonismo" o la "robinsonada" que se entiende como el modo de vida propio de un Robinson, hombre que en la soledad y sin ayuda ajena llega a bastarse a sí mismo. El personaje de la novela se basta a sí mismo para sobrevivir y llevar a cabo las más grandes proezas:

"Así, pues, me puse a trabajar y aquí debo señalar que, puesto que la razón es la sustancia y origen de las matemáticas, todos los hombres pueden hacerse expertos en las artes manuales si utilizan la razón para formular y encuadrar todo y juzgar las cosas racionalmente. Nunca en mi vida había utilizado una herramienta, más con el tiempo, con trabajo, empeño e ingenio descubrí que no había nada que no pudiera construir, en especial, si tenía herramientas; y hasta llegué a hacer un montón de cosas sin herramientas, algunas de ellas, tan solo con una azuela y un hacha, como, seguramente, nunca se habrían hecho antes; y todo ello con infinito esfuerzo" (Defoe, 2017. p. 38). 
Una expresión discursiva del Indeterminismo que en la actualidad se ha convertido en una industria editorial de enormes proporciones son los textos, las terapias y la multiplicidad de eventos que se realizan en torno a la llamada "autoayuda" y sus derivaciones como el "autoconocimiento" o la "autosuperación". El presupuesto ontológico que está en la base de todas estas propuestas es el ser humano que se hace a sí mismo, la conciencia soberana radicalmente libre como la explicación del destino y el comportamiento humanos. Esta expresión discursiva, si bien es ampliamente controvertida en el mundo de las ciencias sociales, en las que son hegemónicos los determinismos unicausales o multicausales, no deja de tener lugar en ciertas prácticas psicoterapéuticas, especialmente las inspiradas en la llamada Psicología Humanista.

En el campo de la comprensión del comportamiento individual y colectivo del ser humano, el Indeterminismo radical que afirma la autodeterminación plena del ser humano tiene la consecuencia problemática de situar la explicación de sus acciones en su libre arbitrio, con lo cual la influencia de factores sociales, históricos y culturales puede ser escamoteada, generándose una explicación tautológica de los fenómenos sociales por los agentes que los encarnan, por ejemplo, explicar la existencia de la violencia por los violentos, la drogadicción por los drogadictos, la prostitución por la prostitutas, etc., con lo cual se dejan por fuera los factores sociales. Es por ello que se dice que el Indeterminismo radical produce una hiperresponsabilización individual que deja de lado las determinaciones sociales. Tal hiperresponsabilización deja también condicionada la libertad, pues esta deja de ser analizada a la luz de las estructuras sociales en las cuales el sujeto desarrolla sus acciones, y se dirige hacia las fluctuaciones de la conducta individual en un contexto fluctuante y azaroso (Restrepo, 2013). De esta forma, Determinismo e Indeterminismo restringen la posibilidad de la libertad y el devenir de lo humano, del actor social en interacción.

\section{El Interaccionismo}

El Interaccionismo no es solamente una perspectiva teórico-metodológica en el campo de las Ciencias Sociales, antes de ello es una doctrina filosófica que ofrece una resolución dialéctica a la dicotomía entre el Determinismo y el Indeterminismo. La visión interaccionista del ser humano es la de un sujeto situado, en parte determinado, en parte sujeto de probabilidades y en parte abierto a la libertad y a la creatividad, un sujeto que construye con otros su propio mundo, a la vez que es construido por los otros en las interacciones. Mientras que para el Determinismo el ser humano es "determinado" y para el Indeterminismo es "determinante", para el Interaccionismo es emergente de los procesos de interacción. La clave para poder comprender esta noción de emergente en el Interaccionismo Simbólico es traer también dos 
conceptos claves: el de actor y el de reflexividad, pues si bien la emergencia ocurre como resultado de la interacción, ella no se puede pensar como determinada por aquello que le es previo, pues allí el actor -la persona- desde su reflexividad -volverse objeto de sí, de su miradainteractúa con el universo simbólico que habita para crear otras posibilidades. Es allí que se presenta la emergencia, como una nueva posibilidad que contiene tanto lo que había como lo nuevo que propone el actor, en una mezcla de lo instituido y lo instituyente, donde coexiste lo que había y lo nuevo que se instala por la vía de la libertad y la creatividad. Debe entenderse aquí que el Interaccionismo Simbólico no niega la relación de los fenómenos con causas que les son anteriores, en lo que sí hace énfasis es en que estas causas no se proponen como una marca inexorable de una línea de hechos que llevará a un fin, sino que, con la acción creativa y libre del actor, la vida misma está sujeta a la posibilidad de lo nuevo, lo no planeado.

Para la perspectiva interaccionista el Determinismo es necesario pero insuficiente para comprender la condición humana. George Herberth Mead propone que las interacciones humanas acontecen en un universo simbólico y que la misma subjetividad humana está estructurada como un proceso de autointeracciones simbólicas (Mead, 1982). Es por esto que Herbert Blumer, denominó "Interaccionismo Simbólico" a la perspectiva teórica y metodológica que inauguró Mead en el campo de las Ciencias Sociales (Blumer, 1982).

Mead afirmaba que la persona es emergente. Para el autor, lo emergente significa una reorganización, una indeterminación relativa, la aparición de algo que antes no estaba, es decir, elementos inéditos que no pueden explicarse exclusivamente desde una perspectiva determinista causal. Se trata de algo nuevo que aparece en el encuentro de cada ser humano con los otros y con la comunidad (Mead, 1982). Este principio lo podríamos llevar a otros campos para mostrar que la subjetividad humana no es un a priori de la interacción sino un emergente de la misma.

La noción de lo emergente renuncia a explicar el presente exclusivamente como el producto de una causalidad mecánica única o múltiple de los eventos pasados. En esta perspectiva interaccionista, Mead propone la noción del self, el "sí mismo", como una estructura de autointeracciones en la que cada ser humano, gracias a la reflexividad, en parte se construye a sí mismo como un emergente, una entidad distinta que surge de la dinámica entre el " $m i$ " -que representa lo que cada sujeto interioriza de su comunidad- y el "yo"-como experiencia de la persona, lo más singular de la subjetividad, donde reside su capacidad creativa, transformadora, incluso subversiva y transgresora y que da cuenta de una visión dialéctica de la subjetividad, en la que están presentes, en una dinámica concurrente y antagónica lo 
instituido y lo instituyente y cuyo resultado no es plenamente predecible a partir de los elementos que entran en interacción (Mead, 1982). Es a partir de la noción del self que se entiende la conciencia subjetiva y su lugar en la reconstrucción de objetos en el ámbito de la experiencia, así como la reorganización de costumbres y el surgimiento de nuevas instituciones (Mead, 2008). Desde esta posición, la mente no es individual, sino una construcción social.

En los planteamientos de Mead la conciencia implica la relatividad y el sentido de la emergencia, pues en la evolución de la mente humana no sólo aparecen formas nuevas, sino que a partir de la experiencia esas formas son dotadas de nuevos contenidos y cualidades, que corresponden a significados también nuevos que dan lugar a comportamientos y significaciones inéditas (Mead, 1991). Así, el proceso de socialización desde un punto de vista interaccionista corresponde a la dinámica, tensiones y negociaciones en la tríada formada entre el agente en proceso de socialización, los agentes socializadores y la realidad social que el autor llama el "Otro generalizado" (Mead, 1982). En este proceso el agente no es uniformado, sino que recibe un repertorio múltiple sobre cómo llegar a "ser". En este punto es importante aclarar que el interaccionismo le confiere al agenciamiento la condición de un nuevo factor causal. Lo importante es evitar la tentación de proponerlo en una perspectiva unicausal porque se convertiría en un determinismo absoluto, que lejos de resolver la dicotomía entre el determinismo y el indeterminismo terminaría por radicalizarla.

Ese repertorio múltiple de cómo llegar a "ser" es el contexto de la autodeterminación y la libertad humana, entendidas como relativas al rol del agente en sus contextos de interacción; con lo cual se toma distancia, de un lado, del Indeterminismo radical de la consciencia soberana que reclama la libertad plena de los actos humanos que hiper-responsabiliza a los seres humanos haciéndolos la explicación última de cada una de sus acciones y, del otro lado, toma distancia también de los determinismos absolutos propuestos por las perspectivas positivistas, unidisciplinares o multidisciplinares, que los des-responsabiliza en la medida en que explica sus acciones a partir de factores externos e internos sin tener en cuenta su capacidad de agencia.

La visión del ser humano como emergente, implica que la persona no es una estructura estable, una esencia o un dato previo al proceso de interacción, sino que surge en la relación con los otros; he ahí el fundamento del interaccionismo, pues la persona y la realidad de la que ella surge, así como la realidad que ella construye, son emergentes de los procesos de interacción. 
En esta misma vía se inscribe también la Etogenia de Rom Harré, como un enfoque desde el cual puede entenderse que los seres humanos no ofrecen sólo respuestas pasivas a las contingencias diarias de su vida natural y social; los actores sociales se conciben como seres que se evalúan a sí mismos y critican activamente sus propias actuaciones, la dirección que le dan a sus actos depende de los significados atribuidos a una situación y al seguimiento de reglas y planes construidos en las relaciones y acciones sociales (Belli, Aceros, \& Harré, 2015). Esta es la acción de la reflexividad: evaluar-se, criticar-se, como condición de posibilidad de la ética. Somos éticos gracias a la reflexividad. Un animal salvaje no puede ser ético, está gobernado por su información genética, hace lo que sus instintos determinan. Un ser humano, gracias al lenguaje, ante el impulso de alimentarse puede, por ejemplo, indicar-se, incluso obligar-se a no sacrificar una especie en vía de extinción o ante un impulso sexual, puede prohibir-se satisfacerlo sin el consentimiento del otro. En esa posibilidad de indicar-se, prohibir-se, evaluar-se, juzgar-se, permitir-se, incluso obligar-se, radica la posibilidad que tiene el ser humano de ser ético. En la reflexividad residen sus márgenes de libertad, de indeterminación y su condición de sujeto ético y político.

De esta forma, el presupuesto ontológico en el Interaccionismo Simbólico postula un ser humano como agente social activo, reflexivo y creativo, transformador de la realidad, que deja sus marcas en el universo simbólico que habita. La condición reflexiva implica que el ser humano puede tomarse a sí mismo como objeto y, hasta cierto punto, ser el autor de su propia construcción. Mead reafirma esta condición cuando expresa: "la persona tiene la característica de ser un objeto para sí, y esa característica la distingue de otros objetos y del cuerpo" (Mead, 1982:127). Para que el individuo pueda ser objeto de sí mismo no hay otra vía que la autointeracción, -que como ya dijimos es un proceso dialéctico en el que interactúan el "mí", como representante del "Otro generalizado" y el "yo" como fuente de la transformación, la creación, la transgresión, e incluso la subversión de ese mismo orden interiorizado en el "mí". Nos vemos a partir de lo que los otros miran en nosotros, y en ese mismo sentido, los otros se convierten en objetos en la interacción con nosotros como interlocutores. Por ello para Mead "la naturaleza humana es esencialmente social" (Mead, 1982, p.130).

Otro aspecto fundamental de la perspectiva ontológica que se deriva del Interaccionismo Simbólico tiene que ver con poner en primer plano la pluralidad del ser humano: somos varias personas, plurales y distintas en cada interacción. Mead presenta a la persona como relativa y situada: "una personalidad múltiple es en cierto sentido normal (...). Por lo general existe una organización de toda la persona con referencia a la comunidad a la que pertenecemos y a la situación en que nos encontramos "(Mead, 1982, p.132). 
Ahora bien, la condición del ser humano como agente activo, transformador y re-creador de su mundo es relativo a los recursos físicos y simbólicos de los que pueda hacer uso cada actor, lo que implica también la asunción de la responsabilidad y la ética como puntos centrales en la comprensión de los actos humanos (Belli et al., 2015).

Esta particular ontología que se deriva del Interaccionismo Simbólico y la Etogenia, permiten construir una perspectiva de los seres humanos que propone una alternativa a la victimización y patologización deterministas de un lado y a la culpabilización y criminalización indeterministas del otro, con relación a los sujetos que encarnan diferentes fenómenos sociales como la drogadicción, la delincuencia, etc., y contribuye a la construcción de una visión más acorde con su realidad de agentes que pueden dar cuenta de su capacidad de agenciamiento relativa a su rol y a la definición de su situación en sus contextos de interacción y de su papel transformador a partir de su capacidad para resignificar lo vivido y darle un nuevo estatuto a lo que construirán como futuro, es decir, como actores que no necesariamente son responsables de lo que les ocurrió pero si pueden hacerse responsables de lo que hacen con lo que les ocurrió. Así se reafirma la etogenia, en acciones de personas mediadas por los significados, y no solo como respuestas de individuos a un repertorio de estímulos (Pons, 2010).

En este punto cobra importancia el concepto de institución en los planteamientos de Mead. Cuando se trata de la interacción entre la persona y la comunidad en la cual se desenvuelve, puede ocurrir que ésta última actúe de manera uniforme, lo que da lugar a la institución como práctica social objetivada lingüísticamente que regula las acciones de los individuos. Pero, al tratarse de una relación dinámica donde las personas se resignifican y con ello se rehacen y consecuentemente tienen la responsabilidad por los cambios necesarios, se puede desplegar la capacidad del individuo en tanto persona de interpelar a esa comunidad por sus estatutos y reformar el orden de las cosas: "el proceso de la conversación es un proceso en que el individuo tiene, no sólo el derecho, sino también el deber, de hablar con la comunidad de la cual forma parte y de provocar los cambios que se llevan a cabo gracias a la interacción de los individuos. Naturalmente, tal es la forma en que la sociedad progresa, precisamente mediante interacciones como aquellas en que una persona piensa acerca de una cosa" (Mead, 1982, p.150).

Para darle fuerza a la idea de una interacción que funda cambios institucionales, es importante resaltar los aportes de William Thomas y Florian Znaniecki, contemporáneos de Mead en la Escuela de Chicago, cuna del pensamiento sociológico interaccionista. En su obra El campesino polaco en Europa y en América, Thomas y Znaniecki (2004) dan cuenta de una de las primeras 
investigaciones interaccionistas, se trata del análisis de textos extraídos de la correspondencia entre inmigrantes polacos que vivían la ciudad de Chicago y sus familias aún en su país de origen. En estas cartas se evidencia el rol que juega el nuevo universo simbólico, el Otro generalizado que construye la comunidad de los inmigrantes en sus interacciones con el país receptor y se muestra la dinámica de las interacciones entre los emisarios de las cartas y los cambios que estas interacciones generan en la subjetividad de tales actores a partir de los nuevos acontecimientos vividos. En palabras de Ken Plummer, quien escribe el prólogo del libro: "Incorpora un tema teórico de igual importancia -los lazos entre subjetividad y objetividad en la investigación social (...) un excelente ejemplo de visión humanística en las ciencias sociales" (Thomas \& Znaniecki, 2004, p.12).

\section{El Interaccionismo Simbólico de Mead y el "Argumento en favor del Indeterminismo" de Karl Popper}

En un texto póstumo de Karl Popper titulado "El universo abierto: un argumento a favor del Indeterminismo", el autor examinó, develó y criticó los problemas del Determinismo en el campo de las ciencias. Para él, no hay Determinismo Científico, y "todo determinismo es metafísico" (Popper 1994, p.36). En este texto afirma que Albert Einstein es el caso paradigmático de un científico que siguió siendo determinista, a pesar de que sus propios descubrimientos le pusieron en evidencia la refutación del determinismo. Según Popper, Einstein "pudo haber creído en el determinismo "científico" en sus años de formación, más tarde, en su vida, su determinismo era francamente de un carácter religioso y metafísico" (Popper, 1994, p.111).

En los textos del último período de su vida, algunos de los cuales solamente se publicaron de manera póstuma, Popper ofrece un marco para comprender lo que él llama el "Determinismo Científico", calificándolo como una doctrina en la que sustituye la idea de dios por la idea de la naturaleza y la idea de la ley divina por la idea de una ley natural. La diferencia estaría dada en que para los creyentes los designios de Dios son inescrutables, mientras que para los científicos las leyes de la naturaleza podrían ser descubiertas por la razón (Popper, 1994).

Popper presenta dos argumentos iniciales a favor del Indeterminismo: el carácter aproximado del conocimiento que produce la ciencia y la asimetría entre el pasado y el futuro. A estos le agrega uno más, a saber, que según el autor es imposible predecir de qué forma va a aumentar nuestro propio conocimiento de las cosas y la forma como este conocimiento se enlazará con la afectación que hagamos sobre la realidad de su entorno. 
Con sus postulados, Popper nos ayuda a comprender su crítica al Determinismo radical, que presenta la realidad individual y social como un libro escrito que se desarrolla según un guion inexorable. En el texto mencionado, Popper se considera a sí mismo indeterminista, pero también se distancia de la perspectiva más radical del Indeterminismo que afirma la libertad absoluta de una conciencia soberana: "Quiero exponer aquí las razones que tengo para ser indeterminista. No incluiré entre ellas la idea de libre albedrío: como argumento racional a favor del indeterminismo es inútil” (Popper, 1994, p.25).

Para argumentar su Indeterminismo en el campo de la física, el autor se apoya en los llamados "saltos cuánticos" sucesos impredecibles que no están controlados por una ley causal ni por la coincidencia de varias, sino solamente por las leyes de la probabilidad: "no están predeterminados y por lo tanto no pueden ser predichos por muy grande que pueda ser nuestro conocimiento de todas las condiciones previas al suceso" (Popper, 1994, p.147). En el texto de Popper, la referencia a la física cuántica y a la introducción del factor probabilístico como elemento necesario para la explicación de los saltos cuánticos, no se hace como argumento en favor del determinismo, sino, al contrario, para mostrar que hay fenómenos que no están plenamente determinados. En esta perspectiva para explicarlos se requiere una perspectiva como la probabilística que vaya más allá del Determinismo Laplaciano. Por ello, el Indeterminismo que Popper propuso tenía en vista dos expresiones, una de ella es la "probabilística" y la otra es la abierta. Esta última es más radical y es la que representa la expresión más clara de la libertad y la creatividad.

En otro artículo titulado El Indeterminismo no basta, que fue publicado como epílogo del texto póstumo: El Universo Abierto, un argumento en favor del Indeterminismo, el autor declara abiertamente la razón de su interés por el Indeterminismo, así como los límites que esta postura observa: "el Indeterminismo es necesario pero insuficiente para permitir la libertad humana y en especial la creatividad" (Popper, 1994, p.148).

Para sustentar su argumento en favor de un Indeterminismo relativo, Popper desarrolla una teoría de tres mundos en interacción, donde el Mundo 1 es el mundo de la física y los fenómenos naturales en general, incluyendo el mundo de lo biológico; El Mundo 2 es el mundo psicológico, la mente humana, pero también la mente animal, incluye los sentimientos, lo consciente y lo inconsciente, lo subjetivo y lo intersubjetivo, las acciones y las interacciones sociales; El Mundo 3 corresponde al mundo de los universos simbólicos productos de la mente humana, se incluyen las obras de arte, los valores éticos, las instituciones sociales, la ciencia. Popper enfatiza que en este Mundo 3 están los problemas científicos y las teorías (incluidas las 
erróneas). El autor propone que la creación del espacio para la libertad humana no puede entenderse sólo cuando se trae a escena el Indeterminismo. Según Popper, hace falta comprender la apertura causal entre los mundos. Se necesita "una apertura causal del mundo 1 hacia el mundo 2, y la apertura causal del mundo 2 hacia el mundo 3 y viceversa" (Popper, 1994, p.136).

La apertura causal entre los mundos nos permite avanzar en los planteamientos de Popper hacia la conclusión que presenta en su escrito, y es que el Indeterminismo no basta. El Indeterminismo es indispensable para entender la libertad y las creaciones humanas en el campo del arte, la ciencia y la vida social e individual, pero no es suficiente porque las creaciones, los acontecimientos inéditos y los eventos instituyentes de los seres humanos no son creaciones ex nihilo, o que surgen de la nada, tampoco emergen en una perspectiva de libre albedrío radical, sino que se introducen en un campo situado, social e históricamente, que tiene sus propias leyes, con lo cual se trata de una afirmación de la libertad y la potencia creadora de sujetos situados.

En el universo propuesto por Popper, en una perspectiva completamente afín con el Interaccionismo Simbólico, se acepta que los fenómenos humanos son en parte determinados; en parte probabilísticos -que no pueden predecirse de una manera absoluta pero sí señalar un conjunto limitado de posibilidades-; y en parte abiertos, es decir emergentes: se trata de una triple condición. En este sentido, la interacción no sólo debe entenderse como la relación entre los tres mundos, sino también como las interacciones entre los seres humanos.

Esta condición del ser humano como sujeto del lenguaje, es decir, habitante del Mundo 3, el de los universos simbólicos, tiene implicaciones fundamentales para el presupuesto ontológico del Interaccionismo Simbólico, ya que el lenguaje es la condición sine qua non de la reflexividad, que es una posibilidad exclusiva de los seres hablantes, de quienes son a la vez sujetos y objetos de sus propias acciones. Gracias a la reflexividad los seres humanos podemos tomarnos a nosotros mismos como objetos de amor y de odio, de idealización y de crítica, podemos interiorizar las interacciones y las estructuras sociales. Por esto, la subjetividad humana hay que comprenderla ante todo como una estructura de auto-interacciones, en la que están presentes las interacciones sociales y sus estructuras, pero en la que también hay una interacción dialéctica entre lo instituido y lo instituyente, entre lo determinado y el agenciamiento, entendido este último como la capacidad de creatividad y los márgenes de autodeterminación y libertad del ser humano. Eso permite a George Mead decir: "La persona, en cuanto puede ser 
un objeto para sí, es esencialmente una estructura social y surge en la experiencia social" (Mead, 1982, p.130).

Lo emergente es una noción especialmente fuerte en Mead, que luego aparecerá en la obra de Popper con un sentido similar: como un inédito que emerge producto de un proceso de interacción, en el que la comprensión de lo nuevo que emerge requiere necesariamente remitirse a los elementos que entraron en la interacción, pero que solamente la remisión a esos elementos es insuficiente para comprender dicha emergencia. El ejemplo clásico en el campo de la biología son las mutaciones, que no pueden entenderse sin los elementos que interactuaron para su emergencia, pero que aun conociéndolos no era posible predecir su ocurrencia, antes de que ésta se diera. Mead agrega que el campo social se asemeja al mundo biológico: la interacción entre dos elementos produce resultados emergentes que son cualitativamente diferentes a los elementos que entraron en interacción (Mead, 1982).

Por ello, podemos decir que el Indeterminismo relativo, que encontramos en la propuesta de Popper, presenta una afinidad notable con el presupuesto ontológico del Interaccionismo Simbólico. Ningún ser humano emerge como persona por fuera de los procesos de interacción, que se desarrollan en el Mundo 3 propuesto por Popper: el campo del lenguaje. En este sentido, si la realidad humana es una construcción simbólica intersubjetiva, no podría sino reafirmarse la existencia de múltiples realidades, tantas como versiones de los universos simbólicos construidos por cada comunidad de seres humanos. La construcción social de la realidad le da un lugar al intérprete, un lugar desde el cual puede construir algo que "es" y que "es cierto", de lo que él puede saber y dar cuenta (Berger \& Luckmann, 2001). La labor de interpretación no es entonces una tarea exclusiva de sabios o estudiosos de la realidad, sino que, al estar inmersos en ella, interpretarla tanto como vivirla es condición humana y estamos obligados a hacerlo, aunque no seamos plenamente conscientes de la constante vivencia hermenéutica, una vivencia humana que como humanos estamos en la búsqueda permanente de su sentido (Beuchot, 2011).

\section{Conclusiones}

El Determinismo y el Indeterminismo como perspectivas en la comprensión del comportamiento humano son dos referentes necesarios, pero en pugna, que permiten situar el Interaccionismo como solución dialéctica a esta dicotomía y como perspectiva ontológica y epistemológica que sirve de fundamento e inspiración de múltiples desarrollos en el campo de las ciencias sociales del siglo XX. 
Es importante anotar que dentro del mismo Interaccionismo Simbólico hubo, en sus primeras décadas, un debate entre una perspectiva con profundas raíces positivistas y causales en autores como Manford Kuhn, quien afirmaba que se pueden predecir las acciones de un individuo, pues ellas obedecen a "recetas internalizadas y conscientemente sostenidas" (Kuhn \& McPartland, 1954); y, su opuesto, Blumer, quien en los postulados más indeterministas señala que el sujeto es un organismo activo, un agente que construye su vida antes que cometerse a fuerzas externas (Blumer, 1982).

Concepción Fernández Villanueva asegura en sus escritos que Kuhn fue el autor que conectó la Psicología Social con el positivismo y las corrientes empíricas más ortodoxas de la sociología, allí el self se operacionaliza y se mide, mientras que en la perspectiva de Blumer el Interaccionismo corría el riesgo, según sus críticos, de deslizarse hacia el Indeterminismo radical y convertirse en un idealismo (Fernández, 2003).

Para evitar estos deslizamientos del Interaccionismo hacia el Determinismo y hacia el Indeterminismo, -especialmente este último-, Sheldon Stryker propuso el "Interaccionismo Simbólico Estructural", que aparece como una crítica y a la vez una alternativa al sesgo determinista de Kuhn y al indeterminista de Blumer, reafirmando la vocación dialéctica de esta apuesta teórica que reconoce la presencia de las determinaciones sociales presentes en lo simbólico y la capacidad de los actores sociales de transformar el universo simbólico que habitan y con ello influir en función de su capacidad relativa de agencia en dichas determinaciones mediatizadas por los lenguajes que habitan. Bajo la perspectiva de Stryker "concebir una estructura social significa admitir que existe una realidad social que va más allá de procesos psicológicos individuales, (...) por no mencionar los procesos de interacción social" (Stryker, 1991, p.88). En este orden de ideas Stryker propone dos psicologías sociales: aquella que se soporta en la psicología y aquella que se soporta en la sociología, sosteniendo que no son para nada excluyentes sino que en conjunción dan cuenta de la relación de las estructuras sociales y el poder de creación simbólica de los actores que las habitan. De esta manera se admite en la Psicologia Social Psicológica el impacto de los estímulos sociales en los procesos psicológicos individuales; $y$, en la Psicología Social Sociológica se comprende la profunda reciprocidad entre la sociedad y los individuos, como aquello que fundamenta y explica la interacción social. Es en esta interacción y reciprocidad donde tiene lugar el Interaccionismo Simbólico Estructural como una respuesta a la dicotomía determinismo - indeterminismo, pues allí el individuo deviene en actor que es producto de las instituciones sociales pero que a su vez recrea todo aquello que constituye sus universos de referencia. Es determinado pero es creador 
de nuevas posibilidades simbólicas, es un devenir. He aquí la resolución que propone Stryker a esta dicotomía (Stryker, 1991).

Con los puntos de coincidencia y de divergencia de estos estudiosos, la Escuela de Chicago se convirtió en la cuna de la investigación empírica donde se le reconoce la relevancia de la "aplicación del conocimiento sociológico para la resolución de problemas sociales" (Garrido \& Alvaro, 2007, p.136). Lo que interesa al investigador interaccionista es la "persona" entendida como sujeto situado, es decir, como ser humano en situación, que ha emergido como resultado de las dinámicas de universos simbólicos en contextos particulares, y la forma como ese emergente se reconfigura desde los acontecimientos que dan forma a sus experiencias y a su manera de interactuar con el mundo y con él mismo, para así construir nuevas subjetividades y realidades.

En el texto póstumo de Karl Popper que hemos mencionado, el autor se plantea un problema crucial: "la libertad y la creatividad" de los seres humanos y en un ejercicio admirable de crítica al Determinismo radical; el autor subraya la importancia del Indeterminismo, pero a continuación subraya que no se trata de un Indeterminismo radical, sino de un Indeterminismo relativo.

En la discusión entre Determinismo e Indeterminismo, y bajo los preceptos del Interaccionismo Simbólico y del Indeterminismo relativo, podría decirse que Mead propone que el Determinismo es necesario, pero no suficiente para comprender la condición humana y que Popper, por su parte, propone que el Indeterminismo es necesario para comprender la libertad y creatividad, pero no son categorías suficientes para abordarlas como rasgos distintivos de la condición humana (Popper, 1994). El punto en común, y que permite esta conversación entre ambos, es que se resisten a admitir la dicotomía determinismo vs indeterminismo para abordar la condición humana y generan una propuesta alternativa que supera esta oposición dilemática. Es en este punto en el que se puede construir un diálogo potente y promisorio para las Ciencias Sociales entre el Interaccionismo Simbólico de George Mead y el "Argumento en favor del Indeterminismo" de Karl Popper.

\section{Referencias}

Álvaro, J., \& Garrido, A. (2013). Teoría sociológica y vínculos psicosociales, pp. 45-110. En Álvaro, J. Fundamentos sociales del comportamiento humano. Barcelona: UOC.

Arroyo, S. (2007). Astrología, psicología y los cuatro elementos. Buenos Aires: Kier. Audi, R. (2004). Diccionario Akal de Filosofía. Madrid: Akal. 
Avila, R. (2008). Aproximación al concepto de determinismo. Cuestiones de Filosofía (10), 120134. https://doi.org/10.19053/01235095.646

Belli, S., Aceros, J., \& Harré, R. (2015). "It's All Discursive!" Crossing Boundaries and Crossing Words with Rom Harré. Universitas Psychologica 14(2), 755-768. https://doi.org/10.11144/Javeriana.upsy14-2.iadc

Berger, P., \& Luckmann, T. (2001). La Construcción Social de la Realidad. Buenos Aires: Amorrortu Editores.

Beuchot, M. (2011). Sobre el sentido de la vida, desde una hermenéutica analógica. Notandum (25), 1-8. http://www.hottopos.com/notand25/09-16Beuchot.pdf

Blumer, H. (1982). El Interaccionismo Simbólico. Perspectiva y método. Barcelona: Hora S.A. Borges, J. L. (1998). Ficciones. Madrid: De Bolsillo.

Borges, J. L. (2001). El Aleph. Madrid: De Bolsillo.

Borges, J. L. (2014). Nueve ensayos dantescos. Akhenaton. Epub. http://assets.espapdf.com/b/Jorge\%20Luis\%20Borges/Nueve\%20ensayos\%20dantesco s\%20(8319)/Nueve\%20ensayos\%20dantescos\%20-\%20Jorge\%20Luis\%20Borges.pdf

Castoriadis, C. (1993). El inconsciente y la ciencia. Buenos Aires: Amorrortu.

Defoe, D. (2017). Aventuras de Robinson Crusoe. Buenos Aires: Biblioteca Virtual Universal. Fernández, C. (2003). Psicologías Sociales en el Umbral del Siglo XXI. Madrid: Fundamentos. Garrido, A., \& Alvaro, J. (2007). Psicología Social. Perspectivas Psicológicas y Sociológicas. Madrid: McGraw-Hill/Interamericana de España.

González, W., \& Alcodea, J. (2006). Contemporary Perspectives in Philosophy and Methodology of Science. Netbiblo.

Grunín, J. (2008). Procesos de simbolización y trabajos de historización en la adolescencia. $\begin{array}{llll}\text { Cadernos de Psicopedagogia 1-16. } & \end{array}$ http://pepsic.bvsalud.org/scielo.php?script=sci arttext\&pid=S167610492008000100004

Guamán, K., Hernández, E., \& Lloay, S. (2020). El positivismo y el positivismo jurídico. Revista $\begin{array}{llll}\text { Universidad } y & \text { Sociedad }\end{array}$ https://rus.ucf.edu.cu/index.php/rus/article/view/1642

Heidegger, M. (2015). Carta sobre el humanismo. Obtenido de https://www.ucm.es/data/cont/docs/241-2015-06-16-

Carta\%20sobre\%20el\%20humanismo.pdf

Kuhn, M., \& McPartland, T. (1954). An Empirical Investigation of Self-Attitudes. American Sociological Review 19(1), 68-76. http://www.jstor.org/stable/pdf/2088175.pdf?refreqid=excelsior\%3A2e49d265310c45 57b492ff4ef66644f5

Laplace, P. S. (1952). A philosophical Essay on probabilities. New York: Dover Publications. Mardones, J., \& Ursúa, N. (1982). Filosofía de las Ciencias Humanas y Sociales. Barcelona: Fontamara. 
Mead, G. (1982). Espíritu, persona y sociedad. Desde el punto de vista del conductismo social. Barcelona: Paidós Básica.

Mead, G. (1991). La génesis del self y el control social. Reis, (55), 165-186. https://dialnet.unirioja.es/descarga/articulo/758619.pdf

Mead, G. (2008). La filosofía del presente. Madrid: Centro de Investigaciones Sociológicas.

Miranda, R. (2017). Determinismo, compatibilismo y escepticismo respecto al libre albedrío. Cinta de Moebio, (60), 295-305. https://doi.org/10.4067/S0717-554X2017000300295

Pons, X. (2010). La aportación a la psicología social del interaccionismo simbólico: una revisión histórica. EduPsykhé. Revista de Psicología y Educación 9(1), 23-42. https://dialnet.unirioja.es/servlet/articulo?codigo $=3268858$

Popper, K. (1994). El universo abierto. Un argumento a favor del indeterminismo. Madrid: Tecnos.

Popper, K. (2006). La miseria del historicismo. Madrid: Alianza Editorial.

Popper, K. (2010). La sociedad abierta y sus enemigos. Barcelona: Paidós.

Raglianti, F. (2018). Actores, objetos, figuras: el giro sociomaterial en la teoría de la acción. Cinta de Moebio, (63), 343-356. https://doi.org/10.4067/S0717-554X2018000300343

Real Academia Española. (2017). Diccionario de la Lengua Española. Robinsonismo. http://dle.rae.es/?w=robinsonismo

Restrepo, D. Determinismo/indeterminismo y determinación: implicaciones en el campo de la salud pública. Revista Facultad Nacional de Salud Pública 31(supl 1), 42-26. https://revistas.udea.edu.co/index.php/fnsp/article/view/16636

Salcedo, M. (2010). El determinismo y el psicoanálisis. Revista CES Psicología 3(1), 1-16. https://doi.org/10.21615/1103

San Agustín. (2017). De la gracia y del libre albedrío. Obtenido de Escritura y verdad: http://escriturayverdad.cl/wpcontent/uploads/Teologia/LAGRACIAYELLIBROALBEDRIOAgustin.pdf

Sartre, J.-P. (2017). Rojo sobre Blanco. Obtenido de A puerta cerrada: http://www.rojosobreblanco.org/descargas/A\%20puerta\%20cerrada.pdf

Sófocles. (2001). Edipo Rey. Obtenido de http://www.corchado.org/pdf/edipo.pdf

Stryker, S. (1987). The vitalization of symbolic interactionism. Social Psychology Quarterly 50(1), 83-94.

http://www.csun.edu/ snk1966/Stryker\%20The\%20Vitalization\%20of\%20Symbolic\%20 Interactionism.pdf

Stryker, S. (1991). Consequences of the gap between the two social psychologies. En C. Stephan, The future of social psychology (pp. 83-98). New York: Springer-Verlag.

Thomas, W., \& Znaniecki, F. (2004). El campesino polaco en Europa y en América. Madrid: Centro de Investigaciones Sociológicas y Boletín Oficial del Estado.

Weber, M. (2012). La ética protestante y el espíritu del capitalismo. Madrid: Alianza Editorial. Zuleta, E. (2001). El Quijote un nuevo sentido de la Aventura. Bogotá: Hombre Nuevo Editores. 
Septiembre - diciembre de 2021

Zuleta, E. (2001). Sobre la lectura. Obtenido de Ministerio de Educación: http://www.mineducacion.gov.co/cvn/1665/articles-99018 archivo pdf.pdf 